\title{
Design of Low Noise Amplifier for Wimax Application
}

\author{
M.H. Misran ${ }^{1}$, M.A. Meor Said ${ }^{2}$, A.Salleh ${ }^{3}$, M.A. Othman ${ }^{4}$, \\ M.M. Ismail ${ }^{5}$, H.A. Sulaiman ${ }^{6}$, R.A.Ramlee ${ }^{7}$ \\ Centre for Telecommunication Research and Innovation \\ (CeTRi),FakultiKej.ElektronikdanKej.Komputer,UniversitiTeknikal Malaysia Melaka \\ Hang Tuah Jaya, Durian Tunggal 76100, Melaka, Malaysia
}

\begin{abstract}
In this paper, the design of a low noiseamplifier (LNA) for WiMAX application is preasented. This $L N A$ is design to operate at frequency range $3.3 \mathrm{GHz}$ to $3.8 \mathrm{GHz}$ and the noise figure targeted are less than $2 \mathrm{~dB}$ while gain is more than $10 \mathrm{~dB}$. Transistor ATF-54143 Low Noise Enhancement Mode Pseudomorphic HEMT from Avago Technology will be used to design the LNA because it meet the specifications and recommended by Avago Technology in LNA design for WiMAX application. AWR Microwave Office will be used in simulation for this project and starting from scratch, the LNA will be designed from 2-port network transistor, input and output matching and DC biasing to design a single stage LNA. Two techniques in LNA design which is the Feedback Amplifier (FA) and Balance Amplifier (BA) will be used and simulated to find the best technique which give optimum performance in terms of gain and noise figure. The best technique is the Feedback Amplifier which gives nominal noise figure of $1.02 \mathrm{~dB}$ and gain of $12 \mathrm{~dB}$.
\end{abstract}

Keywords -Balance Amplifier, Feedback Amplifier, Low Noise Amplifier, noise figure, WiMAX

\section{INTRODUCTION}

Termed as the new era in wireless.communications, Worldwide Interoperability for Microwave Access or generally known as WiMAX is the answer to anytime, anywhere access to information, offering reliable Internet connectivity all around the world.

WiMAX can be used for wireless networking in much the same way as the more common Wi-Fi protocol. WiMAX is a second-generation protocol that allows for more efficient bandwidth use, interference avoidance, and is intended to allow higher data rates over longer distances.

WiMAX is expected to offer initially up to about 40 Mbps capacity per wireless channel for both fixed and portable applications, WiMAX can support hundreds of businesses with T-1 speed connectivity and thousands of residences with DSL speed connectivity depending on the particular technical configuration chosen. WiMAX are build to support voice and video as well as Internet data.

WiMAX could potentially be deployed in a variety of spectrum bands: $2.3 \mathrm{GHz}, 2.5 \mathrm{GHz}$, and $3.5 \mathrm{GHz}$ for licensed band and $5.8 \mathrm{GHz}$ for unlicensed band. Telecommunication companies are unlikely to use the unlicensed spectrum widely other than for backhaul, since they do not own and control the spectrum.

The challenge to the WiMAX receiver chain designer is the wide dynamic range of received signal levels due to a highly variable transmission path. The WiMAX receiver's ability to effectively detect signals from a variable transmission path is critical to ensure system efficiency and data accuracy. Because of WiMAX's unique requirements, using a Low Noise Amplifier (LNA) at the RF front end of a WiMAX receiver is the best way to reduce the noise. A LNA is a simpler, space saving and more efficient solution which allows the receiver chain to have variable gain, low current consumption and excellent linearity.

Signal amplification is a fundamental function in all wireless communication systems. Amplifiers in the receiving chain that are closest to the antenna receive a weak electric signal. Simultaneously, strong interfering signals may be present. Hence, these low noise amplifiers mainly determine the system noise figure and intermodulation behavior of the overall receiver [1].

\section{Single Stage LNA}

\subsection{Raw Device Testing:}

To design a LNA, the first step is to do a raw device testing. The testing is made to the heart of the LNA which is the transistor. The transistor will give the LNA a high gain and a low noise figure. The test is made to check the transistor stability and gain by calculation. The calculations are done only for the center frequency

$$
f_{c}=\sqrt{f_{h} \times f_{1}}=\sqrt{3.8 G \times 3.3 G} \cong 3.5 G H z
$$


To arrive at a balance between noise figure, gain and linearity, the device drain source current (IDS) was chosen to be $60 \mathrm{~mA}$ with a $3 \mathrm{~V}$ drain-to-source voltage (VDS); the gate-to-source voltage was $0.59 \mathrm{~V}$ (VGS). The S-Parameter for frequency $3.5 \mathrm{GHz}$ for the chosen IDS and VDS from simulations of AWR

$$
\begin{aligned}
& S_{11}=0.59531 \angle 149.49^{\circ} \\
& S_{21}=4.4315 \angle 42.261^{\circ} \\
& S_{12}=0.084715 \angle 21.523^{\circ} \\
& S_{22}=\square \square .095832 \square \square 169.43^{\circ}
\end{aligned}
$$

Auxilary Condition,

$$
\begin{aligned}
& \Delta=S_{11 .} S_{22}-S_{12 .} S_{21} \\
& \Delta=0.3735 \angle 107.48^{\circ}
\end{aligned}
$$

Rollet's Condition

$$
\begin{gathered}
K=\frac{1-\left|S_{11}\right|^{2}-\left|S_{22}\right|^{2}+|\Delta|^{2}}{2\left|S_{12} S_{21}\right|} \\
K=1.0335>1
\end{gathered}
$$

From Rollet's Condition, the value of $\mathrm{K}$ is found to be greater than 1 . The transistor is in unconditionally stable so there is no need to draw the stability circle for the transistor.

There are three type of gain that the transistor have. The gains are Power Gain, $G_{P}$, Available Gain, $G_{A}$, and Transducer Gain, $\mathrm{G}_{\mathrm{T}}$.

$$
\Gamma_{\text {in }}=S_{11}+\frac{S_{12} S_{21} \Gamma_{L}}{1-S_{22} \Gamma_{L}}
$$

We know that the $\Gamma_{\mathrm{L}}=\Gamma_{\mathrm{S}}=0$

Thus $\Gamma_{\text {in }}=\mathrm{S}_{11}=0.59531 \angle 149.49^{\circ}$

$$
\Gamma_{\text {out }}=S_{22}+\frac{S_{12} S_{21} \Gamma_{S}}{1-S_{11} \Gamma_{S}}
$$

Thus $\Gamma_{\text {out }}=\mathrm{S}_{22}=0.095832 \angle-169.43^{\circ}$

The power gain

$$
G=\frac{P_{L}}{P_{\text {in }}}=\frac{\left|S_{21}\right|^{2}\left(1-\left|\Gamma_{\mathrm{L}}\right|^{2}\right)}{\left(1-\left|\Gamma_{\text {in }}\right|^{2}\right)\left|1-S_{22} \Gamma_{\mathrm{L}}\right|^{2}}=30.4182=14.83 \mathrm{~dB}
$$

The available power gain;

$$
G=\frac{P_{a v n}}{P_{\text {avs }}}=\frac{\left|S_{21}\right|^{2}\left(1-\left|\Gamma_{\mathrm{S}}\right|^{2}\right)}{\left(1-\left|\Gamma_{\text {out }}\right|^{2}\right)\left|1-S_{11} \Gamma_{\mathrm{S}}\right|^{2}}=19.8202=12.97 \mathrm{~dB}
$$

The transducer power gain;

$$
G=\frac{P_{L}}{P_{a v s}}=\frac{\left|S_{21}\right|^{2}\left(1-\left|\Gamma_{\mathrm{S}}\right|^{2}\right)\left(1-\left|\Gamma_{\mathrm{L}}\right|^{2}\right)}{\left|1-S_{22} \Gamma_{\mathrm{L}}\right|^{2}\left|1-\Gamma_{\mathrm{S}} \Gamma_{\text {in }}\right|^{2}}=19.6382=12.93 \mathrm{~dB}
$$

\subsection{Input and Output Matching:}

The RF input matching always plays a key role in an LNA design. It is not only a way to achieve a low $\mathrm{NF}$; it is also the way to obtain higher gain and better input return loss. For the LNA, a stub element matching is used in both the input and output of the LNA. To design the stub matching, the length of the stub, $l$ and the distance of the stub from the load, $d$ need to be found.

$$
B_{1}=1+\left|S_{11}\right|^{2}-\left|S_{22}\right|^{2}-|\Delta|^{2}=1.2057
$$




$$
\begin{gathered}
B_{2}=1+\left|S_{22}\right|^{2}-\left|S_{11}\right|^{2}-|\Delta|^{2}=0.5153 \\
C_{1}=S_{11}-\Delta S_{22} *=0.5948 \angle 152.94^{\circ} \\
C_{2}=S_{22}-\Delta S_{11} *=0.2383 \angle-100.66^{\circ} \\
\Gamma_{\mathrm{S}}=\frac{\mathrm{B}_{1} \pm \sqrt{\mathrm{B}_{1}^{2}-4\left|\mathrm{C}_{1}\right|^{2}}}{2 C_{1}} \\
=1.1786 \angle-159.94^{\circ} @ 0.8485 \angle-152.94^{\circ} \\
\Gamma_{\mathrm{L}}=\frac{\mathrm{B}_{2} \pm \sqrt{\mathrm{B}_{2}^{2}-4\left|\mathrm{C}_{2}\right|^{2}}}{2 C_{2}} \\
=1.4923 \angle 100.66^{\circ} @ 0.6701 \angle 100.66^{\circ}
\end{gathered}
$$

$\Gamma L$ and $\Gamma S$ should be less than 1 . The chosen value is:

$$
\begin{aligned}
& \Gamma_{S}=0.8485 \angle-152.94^{\circ} \\
& \Gamma_{L}=0.6701 \angle 100.66^{\circ}
\end{aligned}
$$

For Source,

$d=0.0064 \lambda_{g}$

$l=0.2122 \lambda_{g}$

For Load,

$d=0.2523 \lambda_{g}$

$l=0.3320 \lambda_{g}$

$\lambda \mathrm{g}$ values can be found by knowing what is the FR4 specification. The FR4 that will be used is having dielectric constant, er value of 4.6 and thickness, $d$ of $1.6 \mathrm{~mm}$.

$$
\begin{aligned}
A & =\frac{Z_{o}}{60} \sqrt{\frac{\varepsilon_{R}+1}{2}+\frac{\varepsilon_{r}-1}{\varepsilon_{r}+1}\left(0.23+\frac{0.11}{\varepsilon_{r}}\right)=1.55766} \\
\frac{W}{d} & =\frac{8 e^{A}}{e^{2 A}-2}=1.8491<2 \\
W & =1.8491(1.6)=2.9585 \mathrm{~mm} \\
\varepsilon_{e} & =\frac{\varepsilon_{r}+1}{2}+\frac{\varepsilon_{r}-1}{2} \frac{1}{\sqrt{1+12\left(\frac{d}{W}\right)}}=3.4577 \\
\lambda_{g} & =\frac{C}{f \sqrt{\varepsilon_{e}}}=0.046 \mathrm{~mm}
\end{aligned}
$$

From the value of $\lambda \mathrm{g}$ that was found, the value of length, $l$ and distance, $d$ of the stubs can be determines. The values are:

For Source,

$d=0.0064 \lambda_{g}=0.2944 \mathrm{~mm}$

$l=0.2122 \lambda_{g}=9.7621 \mathrm{~mm}$

For Load,

$d=0.2523 \lambda_{g}=13.7678 \mathrm{~mm}$

$l=0.3320 \lambda_{g}=15.272 \mathrm{~mm}$

\subsection{Biasing:}

For this project, to design a single stage LNA, a passive DC biasing will be applied at the transistor ATF-54143. It will be accomplished by the use of voltage divider consisting of R1 and R2. The voltage for the divider is derived from the drain voltage which provides a form of voltage feedback through the use of R3 to help keep drain current constant. The values of R1, R2 and R3 can be found as follows: 
Where,

$$
\begin{aligned}
& R_{3}=\frac{V_{d c}-V_{d s}}{I_{d s}}=10 \Omega \\
& R_{1}=\frac{V_{g s}}{I_{B B}}=295 \Omega \cong 300 \Omega \\
& R_{2}=\frac{V_{d s}-V_{g s}\left(R_{1}\right)}{V_{g s}}=1205 \Omega=1200 \Omega
\end{aligned}
$$

$$
\begin{aligned}
& V_{d c}=3.6 \mathrm{~V} \\
& V_{d s}=3 \mathrm{~V} \\
& V_{g s}=0.59 \mathrm{~V} \\
& I_{d s}=60 \mathrm{~mA} \\
& I_{B B}=2 \mathrm{~mA}
\end{aligned}
$$

A few elements such as capacitors and resistor are added to the design which has various functions to help improving the LNA. Without these elements, the LNA will not function correctly and have a very high noise figure and very low gains. The values and function of each component are as follows:

Table 1: DC Biasing Component Summary [2]

\begin{tabular}{|c|c|l|}
\hline Component & Value & Function \\
\hline C2 And C5 & $3.3 \mathrm{Pf}$ & Provide A Low Impedance In-Band RF Bypass For Matching Networks \\
\hline C3 And C6 & $10000 \mathrm{Pf}$ & $\begin{array}{l}\text { Low Frequency RF Bypass Capacitor For Resistor R3 And R4 } \\
\text { Provide A Termination For Low Frequency Mixing Products }\end{array}$ \\
\hline R1 & $300 \mathrm{Ohm}$ & Voltage Divider Resistor \\
\hline R2 & $12000 \mathrm{Ohm}$ & Voltage Divider Resistor \\
\hline R3 & $10 \mathrm{Ohm}$ & $\begin{array}{l}\text { Low Frequency Termination } \\
\text { Keep Drain Current Constant }\end{array}$ \\
\hline R5 & $10000 \mathrm{Ohm}$ & $\begin{array}{l}\text { Low Frequency Termination } \\
\text { Improve Low Frequency Stability } \\
\text { Improve Low Frequency Stability } \\
\text { Provides Current Limiting For The Gate At Enhancement Mode Devices }\end{array}$ \\
\hline
\end{tabular}

\subsection{Feedback Amplifier:}

In designing a LNA, if a good input return loss is desired, the noise figure will be high; if a good noise figure is desired, the VSWR will be high. The best way to resolve these opposing requirements is to obtain as low as possible noise figure and good return loss is by using a feedback network.

According to Nyquist theory, the noise from any impedance is determined by its resistive component [3] and an ideal lossless element will not impact the NFmin if it is applied as the feedback network [4]. In Figure 1, the Zin can be shown as:

$$
Z_{\text {in }}=r_{g}+\frac{1}{j \omega C_{g s}}
$$

In Figure 2, when adding a source inductance Ls in the FET's source lead, the input voltage can be rewritten as:

Since

$$
V_{g}=I_{g}\left(R_{g}+\frac{1}{j \omega C_{g s}}\right)+\left(I_{g}+g_{m} V_{C}\right) j \omega L_{S}
$$

$$
V_{C}=\frac{I_{g}}{j \omega C_{g s}}
$$

Then $\mathrm{V}_{\mathrm{g}}$ can be expressed as:

$$
V_{g}=I_{g}\left(R_{g}+\frac{1}{j \omega C_{g s}}\right)+\left(I_{g}+g_{m} \frac{I_{g}}{j \omega C_{g s}}\right) j \omega L_{S}
$$




$$
V_{g}=I_{g}\left(R_{g}+\frac{1}{j \omega C_{g s}}+\frac{g_{m} L_{S}}{C_{g s}}+j \omega L_{S}\right)
$$

Thus, the equation input impedance is:

$$
Z_{\text {in }}=\frac{V_{g}}{I_{g}}=\left(R_{g}+j \omega L_{S}\right)+\left(\frac{1}{j \omega C_{g s}}+\frac{g_{m} L_{S}}{C_{g s}}\right)
$$

In equation above, the term $\frac{g_{m} L_{S}}{C_{g s}}$ and $j \omega L_{S}$ is an added input impedance introduced by the source inductor, and the added resistive and reactive component both help improve the performance of the LNA.

Normally, LS should be a small inductor optimized according to the Zin. Based on the analysis above, small microstrip lines can be placed in the source based to act as the added input impedance. To further improve the LNA, via-hole (VIA) are introduced on both of the source leads to work as a small inductor.

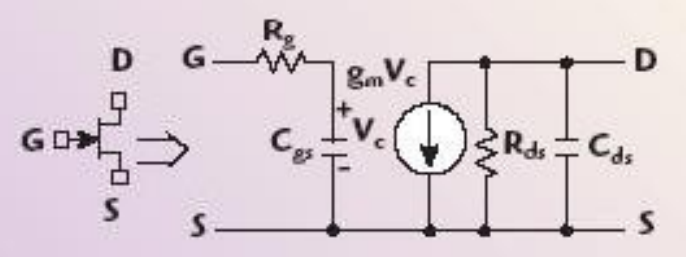

Figure 1: Simplified FET model [6]

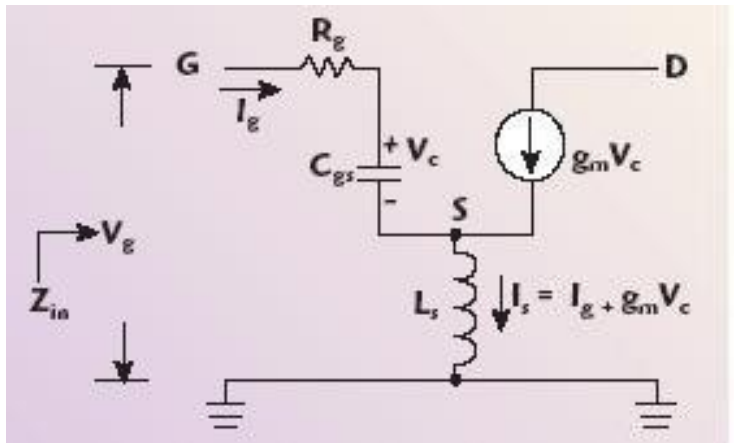

Figure 2: FET model with an external source inductance [6]

Feedback Amplifier which is one of the techniques of broadband amplifier designs is designed and simulated using AWR Microwave Office software. A microstrip lines are inserted at the source based to act as a feedback amplifier. The width and length of the microstrip are tuned in AWR software to find the best possible results for the gain and noise figure.

To further improve the LNA and feedback amplifier, a via-hole (VIA) are added in the designs. The VIA are added after the microstrip lines in the source base of the transistor and the VIA hole diameter, $d$ value are tuned to optimize the gain and noise figure.

\subsection{Balance Amplifier:}

For the balance amplifier design in this project, 3-dB microstrip branch-line couplers are used. Two similar microstrip branch-line couplers will be used to design the balance amplifier. The designs for the $\lambda / 4$ branch line coupler are shown in Figure 3, with $l$ is equal to $\lambda / 4$. There are two value of $\mathrm{Z} 0$ for the branch-line coupler which is $Z 01$ value is $50 \Omega$ and $Z 02$ value is $35.4 \Omega$.

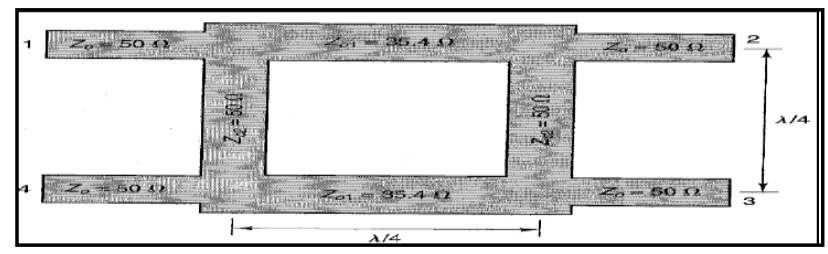

Figure 3: A 3-dB microstrip branch-line coupler [6]

The balance amplifier will be designed in a FR4 with dielectric constant, cr value of 4.6 and thickness, $\mathrm{d}$ of $1.6 \mathrm{~mm}$. To find the value for $\lambda$ for the branch-line coupler, the calculations are shown as follows: 
For $35.4 \Omega$

$$
\begin{aligned}
& B=\frac{377 \pi}{Z_{O} \sqrt{\xi_{r}}}=7.7997 \\
& \frac{w}{d}=\frac{2}{\pi}\left[B-1-\ln (2 B-1)+\frac{\xi_{r}-1}{2 \xi_{r}}\left\{\ln (B-1)+0.39-\frac{0.61}{\xi_{r}}\right\}\right] \\
& \frac{w}{d}=3.163695
\end{aligned}
$$

$d=5.061912 \mathrm{~mm}$

$$
\begin{aligned}
& \xi_{e}=\frac{\xi_{r}+1}{2}+\frac{\xi_{r}-1}{2} \frac{1}{\sqrt{1+12\left(\frac{d}{w}\right)}} \\
& \xi_{e}=3.6222
\end{aligned}
$$

$\lambda_{g}=\frac{c}{f \sqrt{\xi_{e}}}=0.054 m$

The length of $\frac{\lambda}{4}$ for the $\mathrm{Z}_{\mathrm{O} 1}$ is: $\frac{\lambda}{4}=0.01125 \mathrm{~m}$

3.1. Single Stage LNA Design

\section{Simulation}

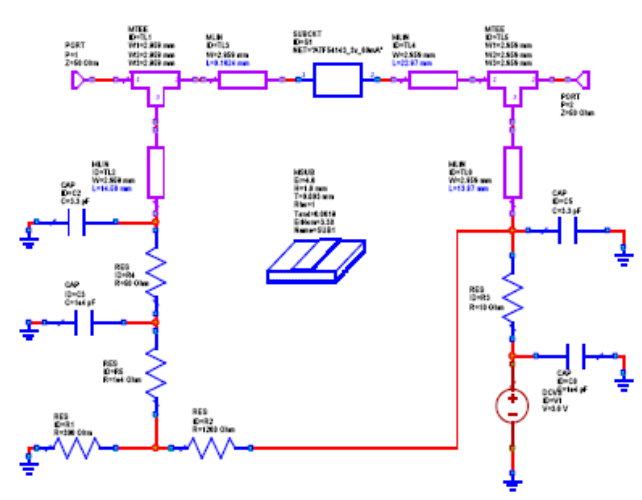

Figure 4: Single Stage LNA

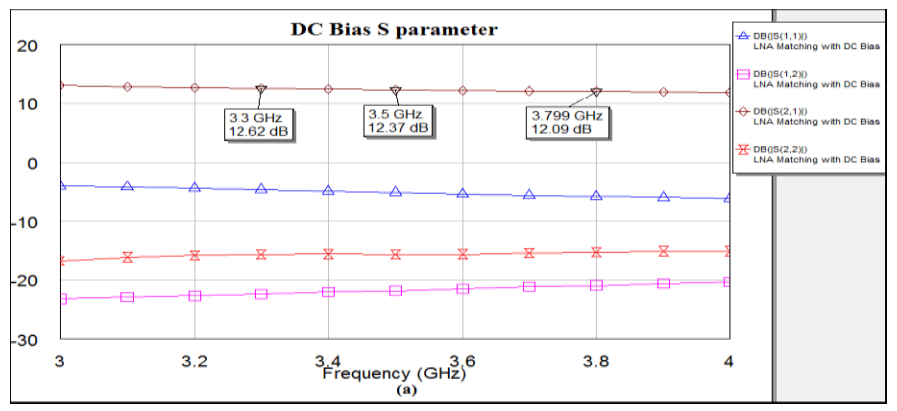




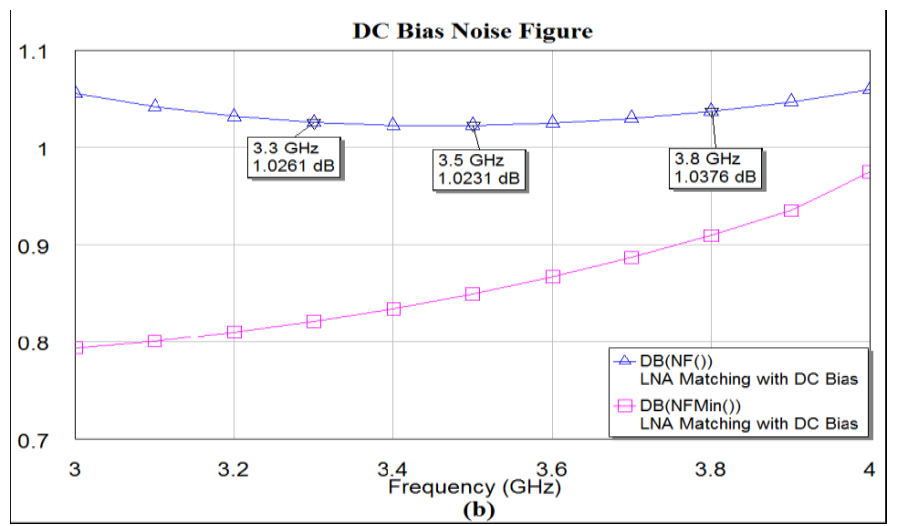

Figure 5: (a) DC Bias S-Parameter analysis (b) DC Bias Noise Figure analysis

Table 2: Gain and Noise Figure of the single stage LNA

\begin{tabular}{|l|c|c|c|c|c|c|c|}
\hline \multicolumn{1}{|c|}{ Parameter } & \multicolumn{3}{|c|}{ Gain, $\mathrm{S}_{21}(\mathrm{~dB})$} & \multicolumn{3}{c|}{ Noise Figure (dB) } \\
\hline Frequency & $3.3 \mathrm{GHz}$ & $3.5 \mathrm{GHz}$ & $3.8 \mathrm{GHz}$ & $3.3 \mathrm{GHz}$ & $3.5 \mathrm{GHz}$ & $3.8 \mathrm{GHz}$ \\
\hline $\begin{array}{l}\text { Single Stage } \\
\text { LNA }\end{array}$ & 12.62 & 12.37 & 12.09 & 1.0261 & 1.0231 & 1.0376 \\
\hline
\end{tabular}

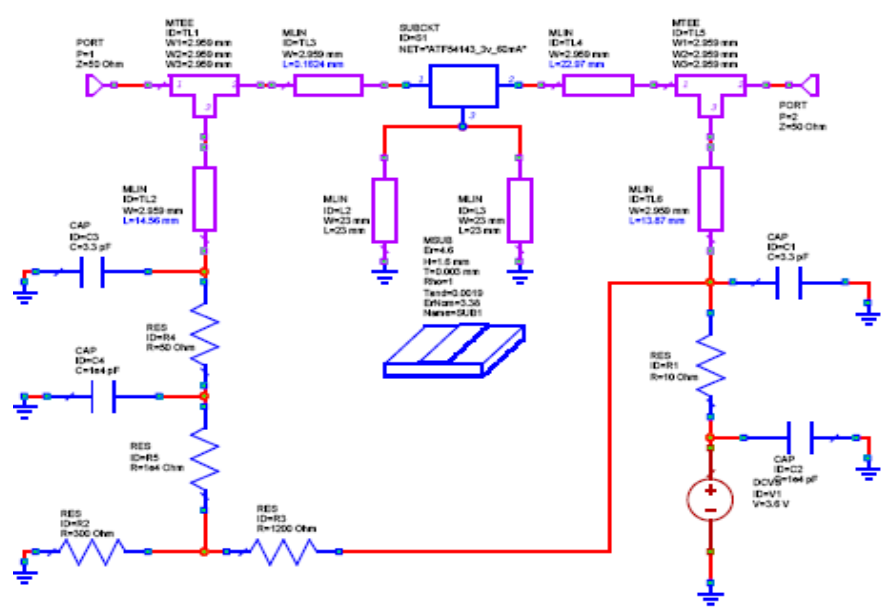

Figure 6: Feedback Amplifier Design

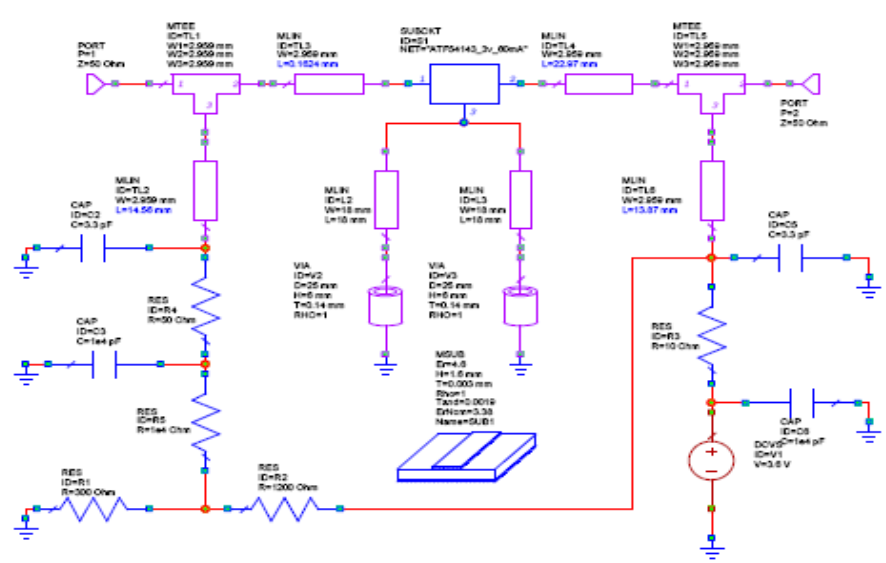

Figure 7: Feedback Amplifier design with VIA 


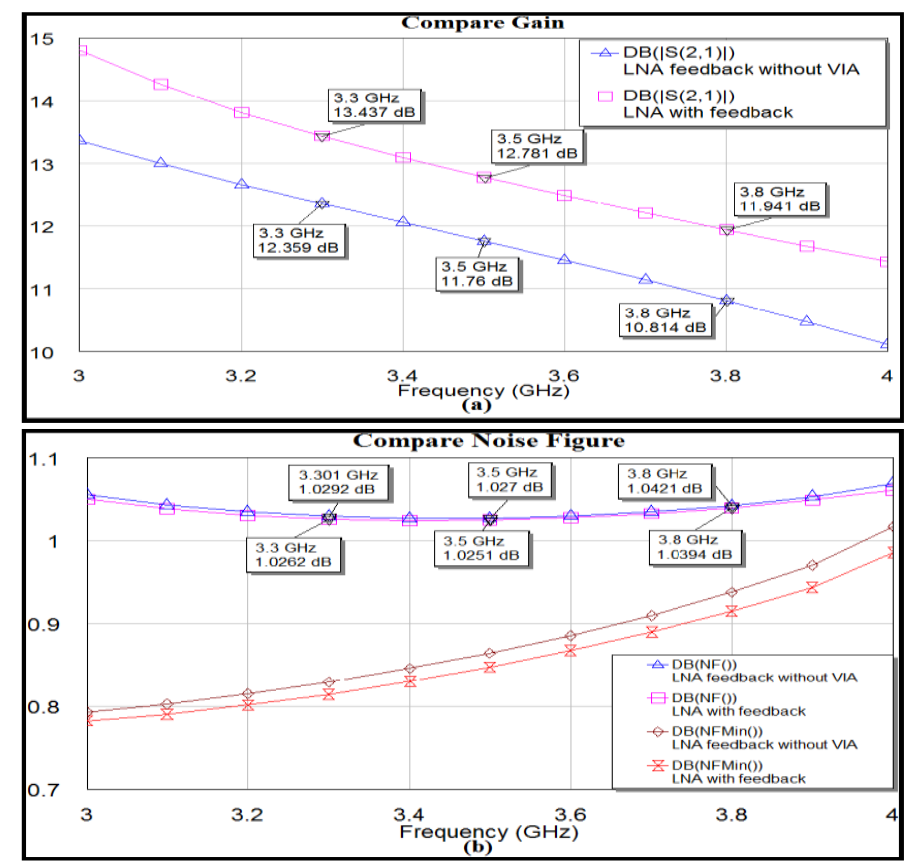

Figure 8: Comparison of Gain for Feedback Amplifier with or without VIA (b) Comparison of Noise Figure for Feedback Amplifier with or without VIA

Table 3: Feedback Amplifier Gain and Noise Figure with or without VIA

\begin{tabular}{|l|c|c|c|c|c|c|}
\hline Parameter & \multicolumn{3}{|c|}{ Gain, $\mathrm{S}_{21}(\mathrm{~dB})$} & \multicolumn{3}{c|}{ Noise Figure (dB) } \\
\hline Frequency & $3.3 \mathrm{GHz}$ & $3.5 \mathrm{GHz}$ & $3.8 \mathrm{GHz}$ & $3.3 \mathrm{GHz}$ & $3.5 \mathrm{GHz}$ & $3.8 \mathrm{GHz}$ \\
\hline $\begin{array}{l}\text { Without } \\
\text { VIA }\end{array}$ & 12.359 & 11.76 & 10.815 & 1.0292 & 1.027 & 1.0421 \\
\hline With VIA & 13.437 & 12.777 & 11.943 & 1.0262 & 1.0251 & 1.0395 \\
\hline
\end{tabular}

\subsection{Balance Amplifier}

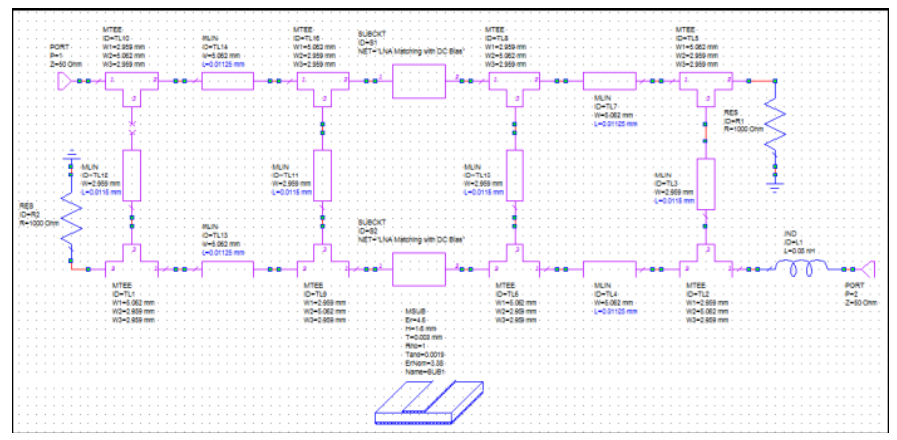

Figure 9: Balance Amplifier Design

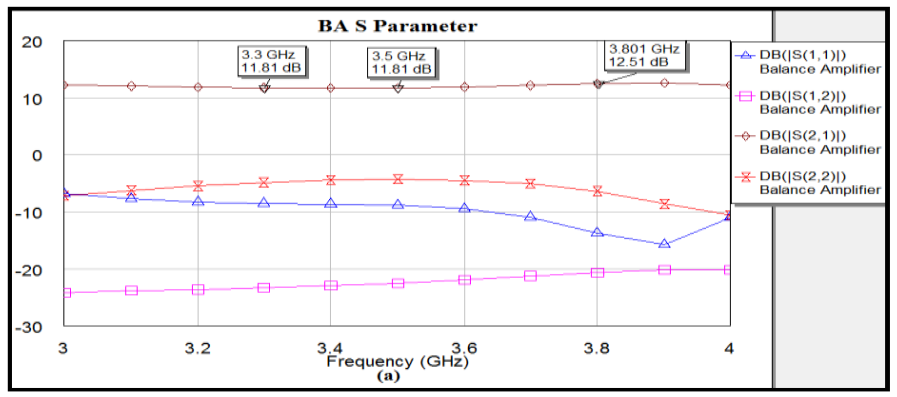




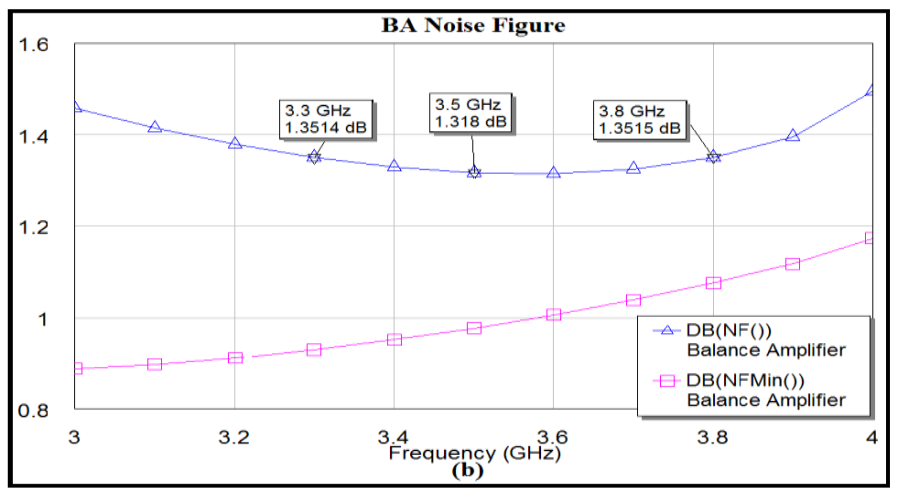

Figure 10: Balance Amplifier S-Parameter analysis (b) Balance Amplifier Noise Figure analysis Table 4: Balance Amplifier Gain and Noise Figure

\begin{tabular}{||l|c|c|c|c|c|c||}
\hline \multicolumn{1}{|c|}{ Parameter } & \multicolumn{3}{c|}{ Gain, $\mathrm{S}_{21}(\mathrm{~dB})$} & \multicolumn{3}{c||}{ Noise Figure (dB) } \\
\hline Frequency & $3.3 \mathrm{GHz}$ & $3.5 \mathrm{GHz}$ & $3.8 \mathrm{GHz}$ & $3.3 \mathrm{GHz}$ & $3.5 \mathrm{GHz}$ & $3.8 \mathrm{GHz}$ \\
\hline $\begin{array}{l}\text { Balance } \\
\text { Amplifier }\end{array}$ & 11.81 & 11.81 & 12.51 & 1.3514 & 1.318 & 1.3515 \\
\hline
\end{tabular}

Figure 11:. Comparison Between Feedback Amplifier and Balance Amplifier

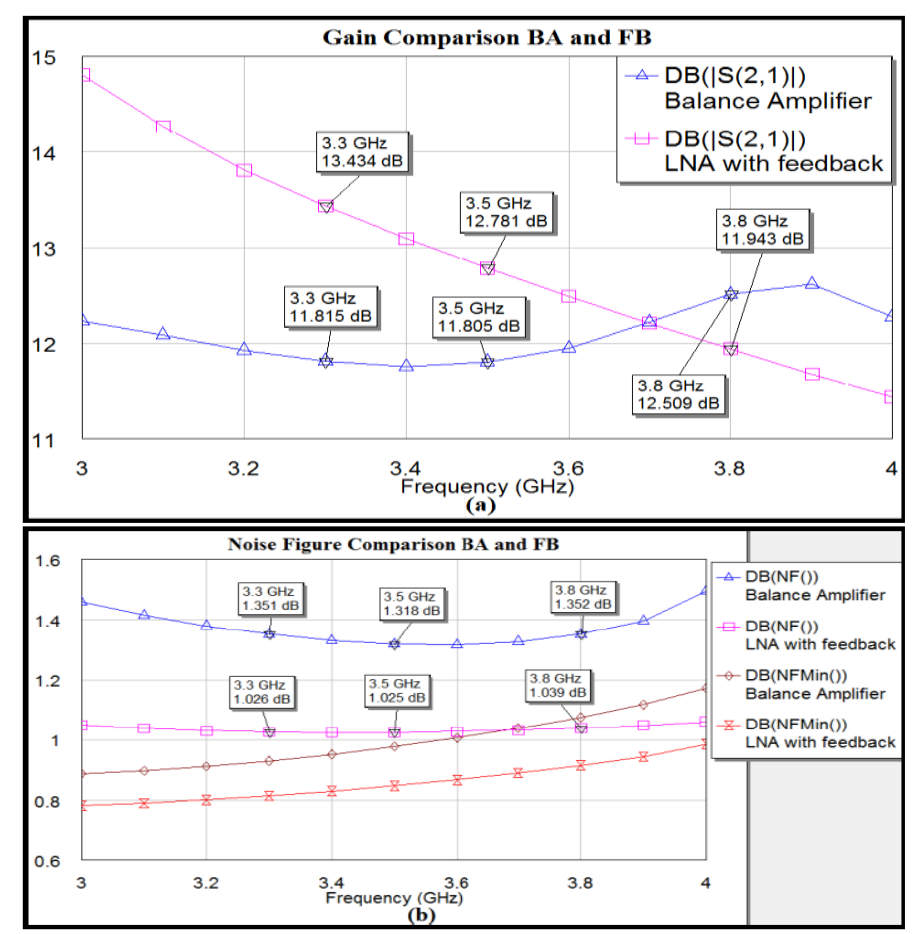

Figure 11: (a) Comparison of Gain for Feedback Amplifier and BA (b) Comparison of Noise Figure for Feedback Amplifier and BA.

Table 5: Comparison between Feedback Amplifier and Balance

\begin{tabular}{|l|c|c|c|c|c|c|}
\hline \hline \multicolumn{1}{|c|}{ Parameter } & \multicolumn{3}{c|}{ Gain, $\mathrm{S}_{21}(\mathrm{~dB})$} & \multicolumn{3}{c|}{ Noise Figure (dB) } \\
\hline Frequency & $3.3 \mathrm{GHz}$ & $3.5 \mathrm{GHz}$ & $3.8 \mathrm{GHz}$ & $3.3 \mathrm{GHz}$ & $3.5 \mathrm{GHz}$ & $3.8 \mathrm{GHz}$ \\
\hline $\begin{array}{l}\text { Feedback } \\
\text { Amplifier }\end{array}$ & 13.437 & 12.777 & 11.943 & 1.0262 & 1.0251 & 1.0395 \\
\hline $\begin{array}{l}\text { Balance } \\
\text { Amplifier }\end{array}$ & 11.81 & 11.81 & 12.51 & 1.3514 & 1.318 & 1.3515 \\
\hline
\end{tabular}

\section{DISCUSSION}


A LNA is design for WiMAX application. WiMAX has two type of frequency spectrum, the licensed and unlicensed band. For licensed band, the frequencies that are used are $2.3 \mathrm{GHz}, 2.5 \mathrm{GHz}$ and $3.5 \mathrm{GHz}$ and for unlicensed band the frequency used is $5.5 \mathrm{GHz}$. This project will design a LNA for frequency range $3.3 \mathrm{GHz}$ to $3.8 \mathrm{GHz}$. The reason this frequency is used because WiMAX in most of the world use frequency band $3.5 \mathrm{GHz}$.

The transistor that is used in designing the LNA is ATF-54143 from Avago Technology. The transistor is chosen because it is recommended by Avago Technology to be used in designing a LNA for WiMAX application and it satisfies the LNA specification which is the maximum noise is $2 \mathrm{~dB}$ and minimum gain is 10 $\mathrm{dB}$. The noise figure and gain are preferably to be lower and higher respectively.

For input and output matching of the component, microstrip stub element matching is used. The length and distance of the stub matching are found by calculation. The gain and noise figure are affected when the stub matching element is inserted in the design. The calculations done are using the center frequency which is 3.5 $\mathrm{GHz}$. The distance and length of the stubs are tuned to optimize the devices to get satisfactory gain and noise figure.

To complete the single stage LNA, DC biasing for the LNA are done using a passive DC bias which use a voltage divider, $\mathrm{R} 1$ and $\mathrm{R} 2$. Then the design is added with capacitors and resistor which functions and values are discussed. After DC bias is implemented in the design, the LNA is degraded in aspect of its gain and noise figure. This is normal because the added element in DC bias affected the gain and noise figure. The single stage LNA satisfies the specification of this project which has nominal gain and noise figure of $12 \mathrm{~dB}$ and 1.02 $\mathrm{dB}$ respectively.

The LNA design is test with two technique of broadband amplifier design which is a Feedback Amplifier and Balance Amplifier. From these two designs, the best technique will be chosen which gave the most satisfactory result for its gain and noise figure. The Feedback Amplifier has the best performance because it has superior value for its gain and noise figure compare to Balance Amplifier.

Both the design met the LNA specifications that have been made before the design started. The design of single stage LNA with Feedback Amplifier technique is chosen in this project LNA design. The design has the highest gain and lowest noise figure compare to single stage LNA with Balance Amplifier. The design has a nominal noise figure of $1.02 \mathrm{~dB}$ and gain of $12 \mathrm{~dB}$.

\section{CONCLUSION}

A single stage LNA are able to design by adding an input and output matching and DC bias in the transistor. To further improve the design, two techniques of broadband amplifier are applied in the design. From two of the design, the Feedback Amplifier design gives the best performance with gain at $12 \mathrm{~dB}$ and noise figure at $1.02 \mathrm{~dB}$. The gain and noise figure that are achieve in the design are following the design specification which is gain more than $10 \mathrm{~dB}$ and noise figure lower than $2 \mathrm{~dB}$.

\section{FUTURE WORK}

From this project, the best design for LNA is the single stage LNA with Feedback Amplifier. In the future, the designs will be fabricated and measured. The fabricated results will be compared to the simulation results for analysis. The fabrication results are important for this project commercialized value for future used.

\section{References}

[1] Mike Golio, Commercial Wireless Circuits and Components Handbook, CRC Press, 2003

[2] I. Bahl and P. Bhartia, Microwave Solid State Circuit Design, John Wiley \& Sons Inc., Hoboken, NJ, 1988 , Chapter 7.

[3] J. Engberg and T. Larsen, Noise Theory of Linear and Nonlinear Circuits, John Wiley \& Sons Inc., Hoboken, NJ, 1995 , Chapter 6.

[4] Xiou Lu, Building a 3.5GHz 802.16a WiMAX LNA on FR4 material, Agilent Technologies, Microwave Journal, Vol. 49, No. 2, February 2006

[5] M. Ben Amor, M. Loulou, S. Quintanel, and D. Pasquet, “A wideband CMOS LNA design for WiMAX applications” Department Of Electrical Engineering, IEEE, July, 2008

[6] Application Note 5331, “A 3.3GHz to 3.8GHz 802.16a WiMAX LNA using Avago Technologies ATF-54143", Avago Technologies

[7] Joseph J. Carr, "Secret of RF Circuit Design”, TAB Electronics, McGraw Hill, 2001

[8] Guillermo Gonzales, "Microwave Transistor Amplifiers Analysis and Design", Second Edition, Prentice Hall, 1997.

[9] Rowan Gilmore and Les Besser, Practical RF Circuit Design For Modern Wireless System, Volume 2, Active Circuits And Systems, Artech House, INC, ISBN: 1-58053-522-4, 2003 